\title{
Design and Control of Single-Phase-to-Three-Phase PFC for Cereals Grinding System Fed by PV-Battery Microgrid
}

\author{
Moustapha Diop ${ }^{1, ~ *, ~ M o u h a m a d o u ~ T h i a m ~}{ }^{2}$, Alphousseyni Ndiaye ${ }^{1,3}$, Samba Gueye $^{1}$, Lamine Thiaw ${ }^{1}$ \\ ${ }^{1}$ Renewable Energy Laboratory, Polytechnic Higher School, Cheikh Anta Diop University, Dakar, Senegal \\ ${ }^{2}$ Laboratory of Science and Technology of Water and Environment, Polytechnic School of Thiès, Thiès, Senegal \\ ${ }^{3}$ Research Team of Energetic System and Efficiency, Alioune Diop University of Bambey, Bambey, Senegal
}

Email address:

moustaphadiop1987@gmail.com (M. Diop)

${ }^{*}$ Corresponding author

\section{To cite this article:}

Moustapha Diop, Mouhamadou Thiam, Alphousseyni Ndiaye, Samba Gueye, Lamine Thiaw. Design and Control of Single-Phase-to-ThreePhase PFC for Cereals Grinding System Fed by PV-Battery Microgrid. American Journal of Electrical Power and Energy Systems. Vol. 8, No. 1, 2019, pp. 33-41. doi: 10.11648/j.epes.20190801.14

Received: December 31, 2018; Accepted: January 28, 2019; Published: March 15, 2019

\begin{abstract}
PV/Battery microgrids hold the most promising solution for providing electricity to remote areas. However, the power quality of these microgrids is vulnerable to nonlinear loads and power electronics components, often necessary to power certain systems such as the cereal grinding systems. These grinding systems consist of mills locally designed driven by induction motors. Given the constraints of microgrids and the structure of the cereal grinding system, a single-phase-to-threephase Power Factor Corrector with two control strategies is proposed. The PFC control is used to control the power quality of the microgrid but also to regulate the DC-link voltage. The field oriented control strategy is used to improve the system efficiency. The performance of the power converter and control strategies are evaluated in simulation under Simulink environment. Results have verified the effectiveness of the proposed controls with a low current Total Harmonic Distortion, a near-unity power-factor and a significant efficiency improvement of cereals grinding system.
\end{abstract}

Keywords: Cereals Grinding System, Microgrid, Single-Phase-to-Three-Phase Converter, Power Factor Corrector

\section{Introduction}

In Senegal, more than $55 \%$ of the population lives in rural areas with an estimated electrification rate of $32 \%$. This low electrification rate has hampered socio-economic progress and contributes to the persistence of poverty with a high rate of food insecurity in rural areas. Thus, to improve the living conditions of populations in rural areas, the electrification issue must be imperatively resolved. This is all the more true since, despite the significant policies efforts, food security and access to drinking water remain important issues in rural areas of the southern and central regions due to the lack of electricity. To solve issues of food security and access to drinking water, significant progresses were noted on the development of water pumping system and grinding system using diesel engines. The use of diesel engines was an attractive alternative for traditional methods. The use of diesel was an attractive alternative to traditional methods.
However, the supply of electricity with diesel is problematic and very expensive for these populations. Despite this real problem, the supply of electricity to rural areas from the national electrical grids is not a viable option, as villages are often too far from the grids. Thus, it is often too difficult and costly to transmit power using extensions of the electrical grid.

To deal with the high cost of grid expansion and the variability in diesel fuel cost, the use of renewable energies has become a more attractive and viable option for providing the required electrical power to rural areas. The production of electricity from renewable energy sources is based on the use of autonomous solar photovoltaic, wind or hybrid systems. However, in Senegal, the wind potential is not high with an average wind speed of $4-5 \mathrm{~m} / \mathrm{s}$ [1]. According to the high solar radiation of $5.8 \mathrm{kWh} / \mathrm{m}^{2} /$ day and 3000 hours of sunshine, the solar photovoltaic is a suitable solution. Thus, for providing electricity to rural areas, decentralized solar photovoltaic energy systems were considered as the best 
options by the Senegalese government [2]. However due to the intermittency of climatic conditions, these decentralized energy systems are equipped with a storage device based on a battery bank. Thus, PV/battery microgrids are becoming attractive options for rural areas and as evidenced by its wide discussions in research [3-7].

Figure 1 shows the global project architecture. The system consists of a PV/Battery microgrid, AC electrical loads (residential house), and public applications (pumping and grinding systems).

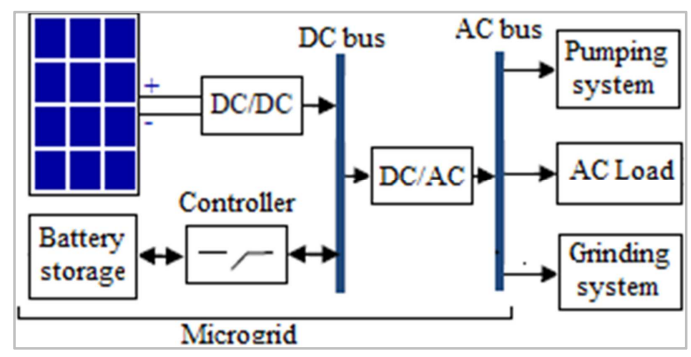

Figure 1. Scheme of the global system.

In order to carry out a complete study of the project, several works are planned in the future. This paper is devoted to the process of feeding the cereals grinding system from the microgrid. The choice to explore cereals processing is all the more important because in Senegal cereals constitute the food base with an annual per capita consumption of $158.2 \mathrm{~kg}$ in rural areas and $107.4 \mathrm{~kg}$ in urban areas. In the past, mills with direct current motors were widely used to grind cereals. Today, the process of mechanization of cereals grinding has progressed by introducing cereals mills locally designed driven by three-phase induction motors powered by microgrids implemented in rural areas. The induction motor is considered to have a high efficiency, robust design with low purchase and maintenance costs requirements [8-10]. Thus its coupling with the mill locally designed makes it possible to design robust and less expensive cereals grinding systems.
In general, the single-phase nature microgrids are considered as weak power systems. To supply the three-phase cereals grinding systems from single-phase microgrid, ACAC power converters are required. However, a large number of conventional power converters generate a large amount of current total harmonic distortion with a low power factor and no sinusoidal current. A high of current total harmonic distortion can have negative effects in the microgrid and results in environmental pollution as electromagnetic interferences and also may cause a shutdown of other equipment [11].

The main aim of this paper is to investigate and propose a Single-Phase-to-Three-Phase PFC converter that provides a sinusoidal input current with a low THD current and a nearunity power factor and regulate the DC-link voltage. This study is also being conducted with the aim of improving the cereals grinding efficiency. Thus, two control strategies are proposed. Power factor control based on the use of current and DC voltage control loops using two Proportional-Integral controllers is used to track a suitable sinusoidal in order to obtain a near-unity power-factor and to regulate the DC-link voltage. The cereals grinding control was achieved using field oriented control to improve system efficiency.

The paper is structured as follows: Section 2 provides a detailed description of the system architecture. The system components modelling are presented in section 3. Section 4 presents control technique of the overall system. The simulation results, which validate the performances of the proposed controls, and the discussions are presented in Section 5. In the end, the conclusion of the paper is presented in Section 6.

\section{Description of the System}

Figure 2 shows the system under study. It consists of a microgrid, a cereals grinding system, an AC-AC power converter and a control circuit.

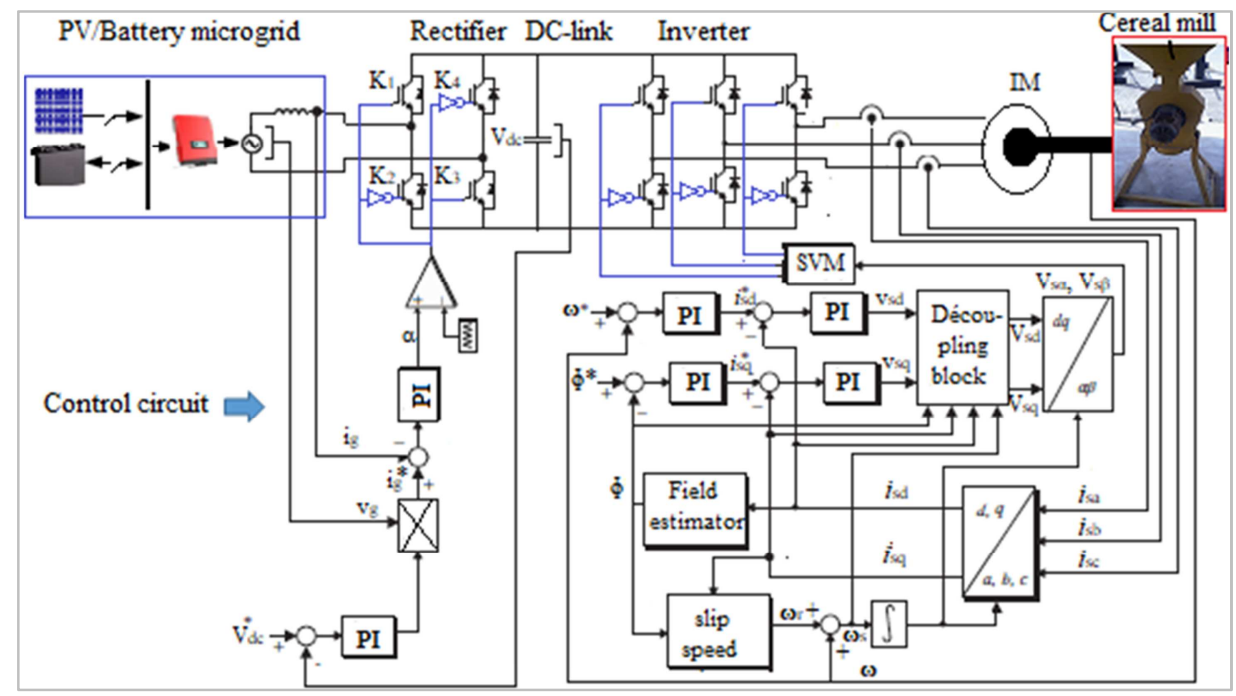

Figure 2. Synoptic of the global controlled system. 
For the microgrid, the photovoltaic system converts directly the sun's radiation into DC electricity. The battery bank is charged from the photovoltaic system using a DC/DC converter that controls the battery stage of charge. The electrical powers generated by the photovoltaic system and battery bank are directly connected to the DC bus. The energy available on the DC bus will be converted by the inverter to power the cereals grinding system. The cereals grinding system consists of a mill locally designed and a three-phase induction motor. To interface the single phase microgrid and the three phase cereals grinding system an ACDC-AC power converter with a control circuit is proposed. The AC-DC-AC converter consists of a rectifier stage and an inverter stage. The control circuit shows that rectifier stage is controlled using the active power factor corrector technique and the inverter is controlled using the conventional Space Vector Modulation technique and the field oriented control.

\section{Modeling of the System Components}

\subsection{PV/Battery Microgrid Modeling}

The photovoltaic system and the battery bank are connected through a common DC bus as illustrated in Figure 3.

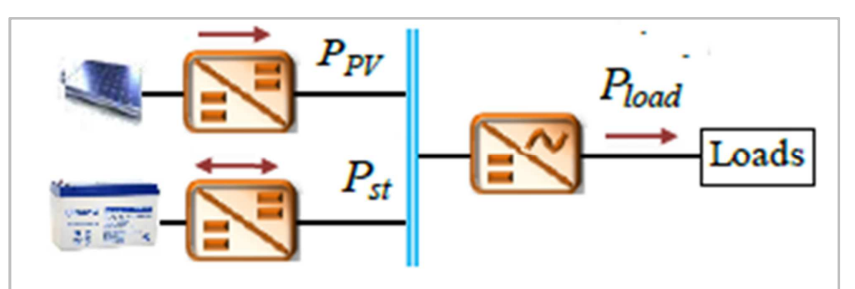

Figure 3. Power flows of the studied microgrid.

The power flows is described in (1)

$$
P_{P V}=P_{s t}+\frac{P_{l o a d}}{\eta_{i n v}}
$$

PV system model: The instantaneous power produce by the photovoltaic system depends to the photovoltaic panel area, the solar irradiation and the ambient temperature Assuming that normal operation cell temperature and temperature under standard test conditions are $44^{\circ} \mathrm{C}$ and $25^{\circ} \mathrm{C}$, the instantaneous power can be calculated by [12]-[16]:

$$
P_{P V}=\eta_{P V S}\left[1-\beta\left(T_{a}-25+30.10^{-3} G\right)\right] A_{P V} G
$$

Battery bank: the battery bank is used to store the surplus of energy from the photovoltaic system. The energy stored is used during low solar radiation or in additional power when the total power consumed by the loads is higher than the power generated by the photovoltaic system. The total power of the storage system can be obtain as follows:

$$
P_{s t}=P_{P V}-\frac{P_{\text {load }}}{\eta_{\text {inv }}}
$$

The battery stage of charge called also SOC is defined according to powers consumed by the loads and then generated by the photovoltaic system.

1) $P_{P V}=P_{\text {load }} / \eta_{\text {inv }}$, the battery SOC should remain constant. The battery is neither being charged nor discharged.

2) $P_{\text {load }} / \eta_{\text {inv }}>P_{P V}$, the battery bank is in discharging state. Thus, the battery SOC will decrease and $\mathrm{P}_{\mathrm{st}}<0$.

3) $\mathrm{P}_{\mathrm{PV}}>\mathrm{P}_{\text {load }} / \eta_{\text {inv }}$, the battery bank is in charging state. In this state, the battery SOC increases and $\mathrm{P}_{\mathrm{st}}>0$.

During the charging and discharging states, the battery SOC versus time can be described by (4) and (5). For the battery safety, the SOC is limited by minimum and maximum allowable states.

$$
\begin{gathered}
S O C(t)=S O C(t-\Delta t)+\frac{\eta_{c h a} \Delta t}{C_{n} U_{b u s}}\left[P_{P V}-\frac{P_{\text {load }}}{\eta_{\text {inv }}}\right] \\
S O C(t)=S O C(t-\Delta t)+\frac{\Delta t}{\eta_{\text {dis }} C_{n} U_{b u s}}\left[P_{P V}-\frac{P_{\text {load }}}{\eta_{D C / A C}}\right] \\
S O C_{\text {min }} \leq S O C \leq S O C_{\text {max }}
\end{gathered}
$$

For sizing the microgrid, a real consumption data of electricity for a small remote village placed in north-west of Senegal village are used. In our case study, a power dispatching based on a solar insolation variation is developed in this work. With the aim of minimizing loss of power supply probability in the village, a sizing method based on three criteria (panels area, powers consumed by the loads and the nominal capacity of the battery bank) are considered to find a best compromise. In the village, the daily average consumption is $20-25 \mathrm{kWh}$ with a power peak of $5 \mathrm{~kW}$. Thus, the configuration of the microgrid is composed of photovoltaic array with an area of $10 \mathrm{~m}^{2}$ and a nominal storage capacity of 1200Ah.

\subsection{Cereals Grinding System Modeling}

The mill is considered as a mechanical load applied to motor shaft. The grinding is the process of reduction of cereals grains to powders by the application of various forces developed by the hammers. The load torque variation versus cereals flow and the rotational speed versus cereals flow represent the general mechanical model of the cereals mill. The induction motor modelling is widely treated in [17] [19]. In d-q reference frame rotating, the electric, magnetic and mechanic equations governing the induction motor operating is given by:

$$
\begin{gathered}
\left\{\begin{array}{l}
v_{s d}=\left(R_{s}+s L_{s} \sigma\right) i_{s d}+\mu s \phi_{r}-\omega_{s} L_{s} i_{s q} \\
v_{s q}=\left(R_{s}+s L_{s} \sigma\right) i_{s q}+\omega_{s} L_{s} i_{s d}+\omega_{s} \mu \phi_{r}
\end{array}\right. \\
\left\{\begin{array}{l}
\phi_{r q}=L_{m} i_{s q}-s T_{r} \phi_{r q}-T_{r}\left(\omega_{s}-\omega\right) \phi_{r d} \\
\phi_{r d}=L_{m} i_{s d}-s T_{r} \phi_{r d}+T_{r}\left(\omega_{s}-\omega\right) \phi_{r d}
\end{array}\right.
\end{gathered}
$$




$$
\left\{\begin{array}{l}
T_{e}=1.5 p \mu\left(i_{s q} \phi_{r d}-i_{s d} \phi_{r q}\right) \\
J_{S} \Omega+f_{r} \Omega=T_{e}-T_{l-m i l l}
\end{array}\right.
$$

Where: $\sigma=1-\frac{L_{m}^{2}}{L_{s} L_{r}} \mu=\frac{L_{m}}{L_{r}} T_{r}=\frac{L_{r}}{R_{r}}$

In [20], the model of the cereals mill is developed. The load torque variation versus cereals flow and the rotational speed versus cereals flow are given by:

$$
\begin{gathered}
\omega=\omega_{0}-\alpha \times Q \\
T_{l-\text { mill }}=a \times Q^{2}+b \times Q+c
\end{gathered}
$$

Where $\square_{\mathrm{o}}, \alpha, \mathrm{a}, \mathrm{b}$ and $\mathrm{c}$ are characteristic parameters of the cereals mill that can be extracted from experiments.

The global efficiency of cereals grinding system is usually expressed as follow.

$$
\eta_{C G S}=\frac{\left(a Q^{2}+b Q+c\right) \omega}{P_{e}}
$$

To determine characteristic parameters, the cereals grinding system has been experimentally characterized using a test bench consists of a small local mill prototype and a $3 \mathrm{HP}$ induction motor. The characterization method consists in varying the cereals flow and taking the speed values and then determining the characteristic torque-speed. The cereals flow variation and control are possible with the adjustment of the mill control valve. The experimental test is done by respecting the operation constraints such as the grinding process is done during steady-state and valve must be well controlled to prevent system jam. Results are presented in Figure 4 and 5.

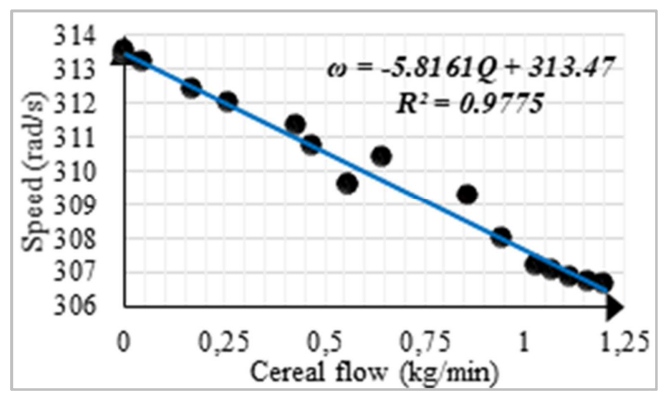

Figure 4. Grinding system characteristic (Speed, Flow)

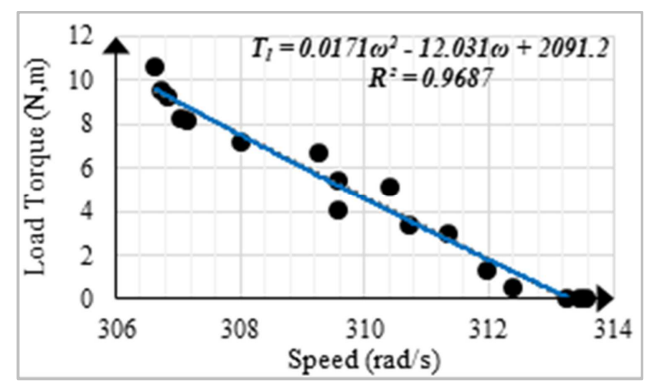

Figure 5. Grinding system characteristic (Torque, Speed).
Characteristic curves variation laws are determined using the trend curve method. Curves are useful for parameters identification of the developed theoretical model mill. Hence, by substituting the (Speed, Flow) equation into the (Torque, Speed) expression, it is possible to develop load torque expression versus Cereal flow. According to characteristic curves, parameters in theoretical equations can be derived directly by identification.

\subsection{Design and Modeling of the Converter}

The power quality and the stability are paramount for the microgrid. Thus, the design of the converter must take into account the microgrid constraints. The power converter must offer possibilities to limit the input current harmonic distortion, improve the power factor, regulate the DC-link voltage and generate a three phase voltage source of variables amplitude and frequency. In fact, a converter which consists of a single phase power factor corrector rectifier and a three-phase inverter converter in cascade connection is proposed. A schematic diagram of proposed converter is shown in Figure 6.

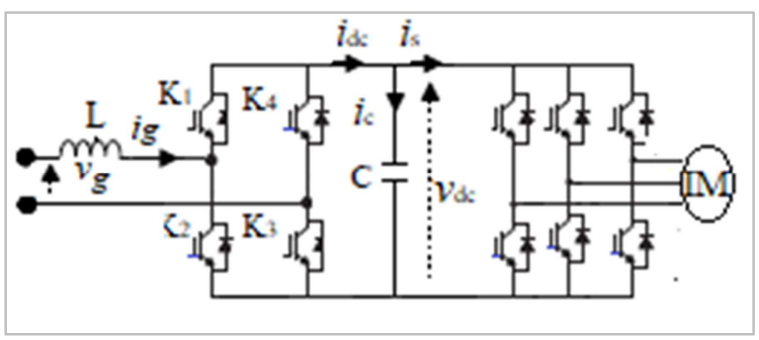

Figure 6. Equivalent circuit of the PFC rectifier converter.

The operating principle of the inverter is based on power switches that supply the grain cereals grinding system with adjustable frequency and amplitude. The converter modeling can be limited to the rectifier modeling. To simplify the rectifier modeling, losses of the input inductor and the output capacitor are neglected, and the semiconductor components are assumed ideal. The power switches $\left(\mathrm{K}_{1}, \mathrm{~K}_{2}, \mathrm{~K}_{3}, \mathrm{~K}_{4}\right)$ define the converter operation according to their state. The equivalent circuit operating principles can be explained by examining the different operating modes depending on the power switches states.

Mode 1: $\left(\mathrm{K}_{1}, \mathrm{~K}_{3}\right)$ are turned on and $\left(\mathrm{K}_{2}, \mathrm{~K}_{4}\right)$ are turned off. The related equation of this operating mode is:

$$
L \frac{d i_{g}}{d t}=v_{g}-v_{d c}
$$

Mode 2: $\left(\mathrm{K}_{2}, \mathrm{~K}_{4}\right)$ are turned on and $\left(\mathrm{K}_{1}, \mathrm{~K}_{3}\right)$ are turned off. The related equation of this operating mode is:

$$
L \frac{d i_{g}}{d t}=v_{g}+v_{d c}
$$

Mode 3 and Mode 4 corresponds to the positive-half-cycle $\left(\mathrm{K}_{1}, \mathrm{~K}_{4}\right.$ are on and $\mathrm{K}_{2}, \mathrm{~K}_{3}$ are off) and the negative-half-cycle $\left(\mathrm{K}_{2}, \mathrm{~K}_{3}\right.$ are on and $\mathrm{K}_{1}, \mathrm{~K}_{4}$ are off) of the voltage source, respectively. During these periods, the inductance is charged 
from input voltage source. The related equation of operating modes 3 and 4 can be derived as:

$$
L \frac{d i_{g}}{d t}=v_{g}
$$

Considering the related equations of these four operating modes and by applying Kirchhoff laws to the output filter capacitor, the rectifier can be modelled analytically in the general case by the following equations:

$$
\begin{aligned}
L \frac{d i_{g}}{d t} & =v_{g}-k v_{d c} \\
C \frac{d v_{d c}}{d t} & =k i_{g}-i_{s}
\end{aligned}
$$

The parameter $k$ denotes the switching function of switches. It is defined as:

$$
k=\left\{\begin{array}{l}
+1 \text { if } \mathrm{K}_{1}, \mathrm{~K}_{3} \text { are } \mathrm{ON} \text { and } \mathrm{K}_{2}, \mathrm{~K}_{4} \text { are } \mathrm{OFF} \\
0 \text { if } \mathrm{K}_{1}, \mathrm{~K}_{4} \text { are } \mathrm{ON} \text { or } \mathrm{K}_{2}, \mathrm{~K}_{3} \text { are } \mathrm{OFF} \\
-1 \text { if } \mathrm{K}_{2}, \mathrm{~K}_{4} \text { are } \mathrm{ON} \text { and } \mathrm{K}_{1}, \mathrm{~K}_{3} \text { are } \mathrm{OFF}
\end{array}\right.
$$

\section{Proposed Control System}

The developed strategies are based on power factor control and field oriented control

\subsection{Power Factor Control}

The control scheme consists of current and DC voltage control loops using two Proportional-Integral controllers as shown in Figure 7 . The outer voltage loop is aimed to regulate the DC link voltage and to stabilize it around a desired value. And, the inner current loop is aimed to provide sinusoidal input current and to improve the input power factor.
For the control principle, output voltage and reference values are compared. The resulting value, passes through the voltage controller, which generates the current reference by multiplying it to the instantaneous voltage source considered as sinusoidal. The difference of reference and sensed inductor currents is fed back to the current controller and the resulting output signal is compared with a fixed frequency carrier wave to generate Pulse-Width-Modulated gating signals for power switches.

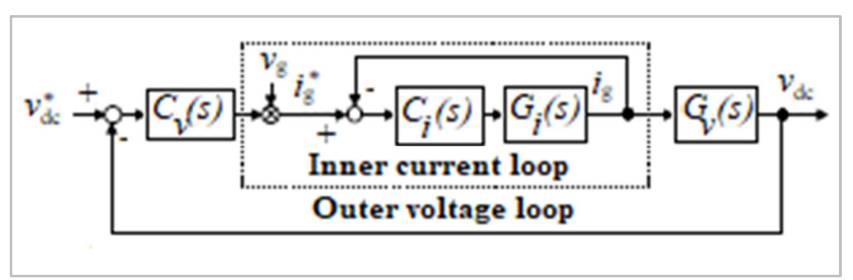

Figure 7. Block diagram of DC voltage and current loops control.

Where: $C_{i}(s)$ and $C_{i}(s)$ are transfer functions of current and voltage PI controllers. It are given by following relations:

$$
\begin{aligned}
& C_{i}(s)=K_{p i}\left(1+\frac{1}{T_{i i} s}\right) \\
& C_{v}(s)=K_{p v}\left(1+\frac{1}{T_{i v} s}\right)
\end{aligned}
$$

To determine the transfer functions for current and voltage loops, the rectifier output is modeled as a nominal resistive $\left(\mathrm{R}_{\mathrm{L}}\right)$ and the input inductor equivalent series resistance $\left(\mathrm{r}_{\mathrm{L}}\right)$ is taking account.

DC link voltage regulation: The voltage and current to be controlled can be defined as quantities with direct components $\left(\mathrm{V}_{\mathrm{dc}}, \mathrm{I}_{\mathrm{g}}\right)$ and variable components $\left(\widetilde{i}_{g}, \widetilde{v}_{d c}\right)$. Thus, the power balance can be written as:

$$
\frac{V_{g}\left(I_{g}+\tilde{i}_{g}\right)}{2}=\left(V_{d c}+\widetilde{v}_{d c}\right) C \frac{d\left(V_{d c}+\widetilde{v}_{d c}\right)}{d t}+\frac{\left(V_{d c}+\widetilde{v}_{d c}\right)}{R_{L}}
$$

Considering that the variable component is very small compared to the direct component, the power balance can be rewritten as follows:

$$
\frac{V_{g} I_{g}}{2}+\frac{V_{g} \tilde{i}_{g}}{2}=C V_{d c} \frac{d \widetilde{v}_{d c}}{d t}+\frac{V_{d c}^{2}}{R_{L}}+2 \frac{V_{d c}}{R_{L}} \widetilde{v}_{d c}
$$

With the assumption of effective power transfer between source and load, the power balance can be expressed as

$$
\frac{R_{L} V_{g} \widetilde{i}_{e}}{4 V_{d c}}=\left(\frac{R_{L} C}{2} s+1\right) \widetilde{v}_{d c}
$$

Thus, the transfer function of the voltage loop can be expressed as follows:

$$
G_{v}(s)=\frac{K_{v}}{1+T_{v} s}
$$

Where $K_{v}=\frac{R_{L} V_{g}}{4 V_{d c}}$ and $T_{v}=\frac{R_{L} C}{2}$

According to transfer function of voltage PI controller and the transfer function of the voltage loop, the closed loop transfer functions of DC-link voltage is given by: 


$$
H_{v}(s)=\frac{1+T_{i v} s}{1+\left(T_{i v}+\frac{T_{i v}}{K_{v} K_{p v}}\right) s+\frac{T_{i v} T_{v}}{K_{v} K_{p v}} s^{2}}
$$

The controller's parameters are determined by using the pole placement method and considering for, the outer loop is designed to be sufficiently slower than the inner loop to ensure the control system stability. The PI controller parameters of the voltage control loop can be calculated using following expressions:

$$
\begin{aligned}
T_{i v} & =\frac{2 \xi \omega_{c v} T_{v}-1}{T_{v} \omega_{c v}{ }^{2}} \\
K_{p v} & =\frac{2 \xi \omega_{c v} T_{v}-1}{K_{v}}
\end{aligned}
$$

Input current control: The instantaneous electrical equation at the converter input can be written as follows:

$$
L \frac{d i_{g}}{d t}+r_{L} i_{g}=v_{g}-v_{r}
$$

The transfer function of current loop is established by applying the Laplace transform to the electrical equation with the assumption that the converter can be modelled by a static gain $G_{s}$, which represents the ratio between the output voltage and the modulation voltages, and that the term $v_{\mathrm{g}}(\mathrm{s})$ is presented as a perturbation. These assumptions allows to establish the following relationship:

$$
\left[L s+r_{L}\right] i_{g}(s)=-G_{s} v_{r}(s)
$$

Thus, the transfer function of current loop is:

$$
G_{i}(s)=\frac{K_{i}}{1+T_{i} s}
$$

$$
\text { Where } K_{i}=\frac{-G_{s}}{r_{L}} \text { and } T_{i}=\frac{L}{r_{L}}
$$

According to (19) and (30), the closed loop transfer function of the current is given by:

$$
H_{i}(s)=\frac{1+T_{i i} s}{1+\left[T_{i i}+\frac{T_{i i}}{K_{i} K_{p i}}\right] s+\frac{T_{i i} T_{i}}{K_{i} K_{p i}} s^{2}}
$$

The controller's parameters are determined by using the pole placement method. It can be calculated using following expressions:

$$
\begin{aligned}
T_{i i} & =\frac{2 \xi \omega_{c i} T_{i}-1}{T_{i} \omega_{c i}{ }^{2}} \\
K_{p i} & =\frac{2 \xi \omega_{c i} T_{i}-1}{K_{i}}
\end{aligned}
$$

\subsection{Field Oriented Control}

The field oriented control has become the most method used for speed and flux controls. This control strategy is based on decoupling the motor torque and fluxes, then the DC motor performance can be achieved [21], [22]. The speed and flux are controlled in external closed-loops control using two PI controllers. Currents components are controlled in internal closed-loops control using two PI controllers [23], [24].

Internal closed-loops: The closed-loop currents scheme using PI controllers is presented in Figure 8.

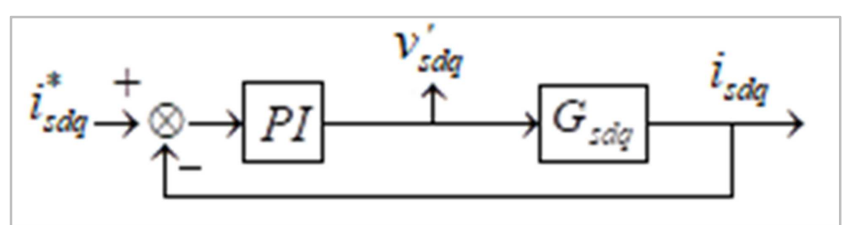

Figure 8. Currents closed loop control.

According to the electrical equations of the induction motor, the controlling terms of stator currents in $\mathrm{d}-\mathrm{q}$ axis are given by:

$$
v_{s d q}^{\prime}=\left(R_{s}+s L_{s} \sigma\right) i_{s d q}
$$

The expression is used to express the current transfer functions.

$$
G_{s d q}=\frac{v_{s d q}^{\prime}}{i_{s d q}}=\frac{1}{R_{s}+s L_{s} \sigma}
$$

The parameters of currents PI controllers are tuned using the pole zero cancellation technique. It has allowed to eliminate the pole zero introduced in the transfer function in closed loop. By introducing the time constant $\tau_{\mathrm{c}}$, the closed loop transfer function and relationships derived of pole zero cancellation technique are given by (36), (37) and (38).

$$
\begin{gathered}
F_{c l}=\frac{1}{1+\tau_{c} s} \\
\frac{L_{s} \sigma}{R_{s}}=\frac{K_{p c}}{K_{i c}} \\
\frac{R_{s}}{K_{i c}}=\tau_{c}
\end{gathered}
$$

Based on these equations, the PI controller parameters can be calculated by followings relations. 


$$
\begin{gathered}
K_{p c}=\frac{L_{s s}}{\tau_{c}} \\
K_{i c}=\frac{R_{s}}{\tau_{c}}
\end{gathered}
$$

External closed-loops: The value and the transfer function of the rotor flux are estimated and expressed using the following expressions:

$$
\phi_{r}=\frac{L_{m}}{T_{r} s+1} i_{s d}
$$

The PI controller gains for closed-loop control are tuned based on pole zero cancellation method. By defining $\tau_{\phi}$ as the time constant, it can be calculated by:

$$
\begin{gathered}
K_{p \phi}=\frac{T_{r}}{\tau_{\phi}} \\
K_{p \phi}=\frac{1}{L_{m} \tau_{\phi}}
\end{gathered}
$$

Speed control is the most important point of this application. Control strategy used in closed loop can allow to determinate the operating speed of the cereals grinding system by a fixing a desired value. The closed-loop speed scheme is shown in Figure 9.

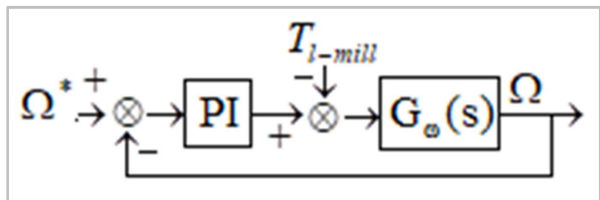

Figure 9. Speed closed loop control.

For the speed loop control, the transfer function of the PI controller is:

$$
C_{i}(s)=K_{p \omega}+\frac{K_{i \omega}}{s}
$$

Based on schematic representation, the speed control equation is:

$$
\left[J_{S}+f_{r}\right] \Omega=\left[K_{p \omega}+\frac{K_{i \omega}}{S}\right]\left[\Omega^{*}-\Omega\right]-T_{l-\text { mill }}
$$

Assuming that the load torque exerted by the cereals grinding system is considered as a perturbation, the closed loop transfer function of the speed can be expressed as follows:

$$
F_{c l}=\frac{\Omega}{\Omega^{*}}=\frac{1+\frac{K_{p \omega}}{K_{i \omega}} s}{\frac{J}{K_{i \omega}} s^{2}+\left(\frac{K_{p \omega}+f_{r}}{K_{i \omega}}\right) s+1}
$$

The closed-loop transfer function is identical to a second order system. Hence, the PI gains are given by (47) and (48).

$$
\begin{gathered}
K_{p \omega}=2 J \xi \omega_{c}-f_{r} \\
K_{i \omega}=J \omega_{c}^{2}
\end{gathered}
$$

\section{Simulation Results}

This section aims to evaluate the proposed control strategies. The simulation was done using parameters given in Appendix. Figure 10 gives the input line current (a), voltage and current waveforms (b) and the current total harmonic distortion (c). For results, the input current is all time sinusoidal and in phase with the supply voltage. The current harmonic distortion is very low and the power factor is about 0.99 . The DC-link voltage for different loads is presented in Fig. 11. From results, it can be seen that it tracks perfectly the fixed reference signal with a good dynamic response. Thus, it can be conclude that the proposed controlled converter has a power factor close to unity with low current harmonic distortion.

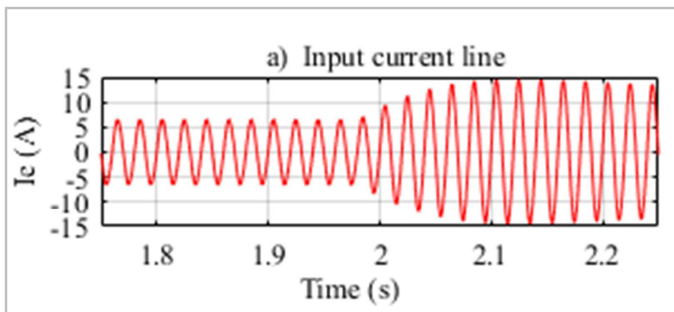

b) Voltage and current line c) THD of current line

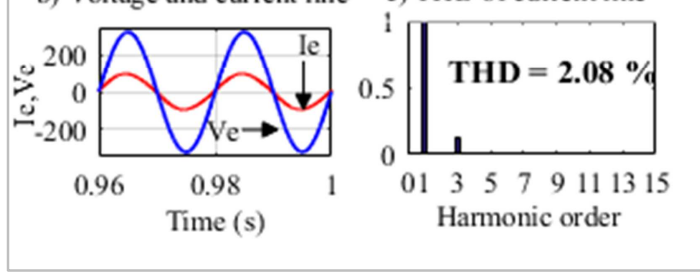

Figure 10. Results for the input current line.

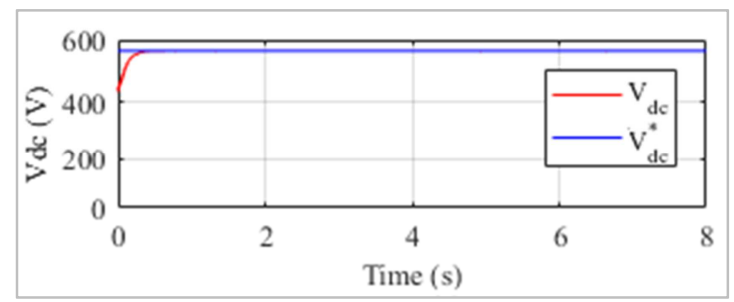

Figure 11. DC link voltage. 


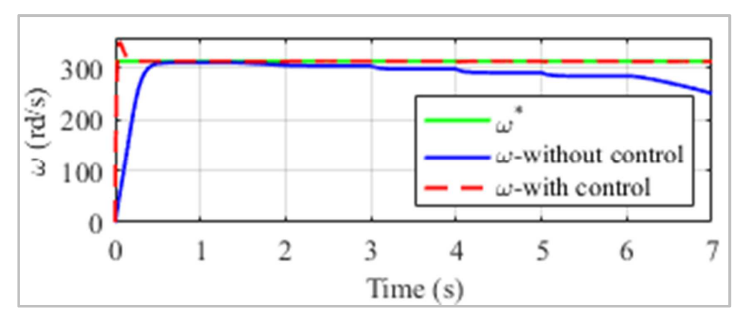

Figure 12. Reference and measured speeds with and without control.

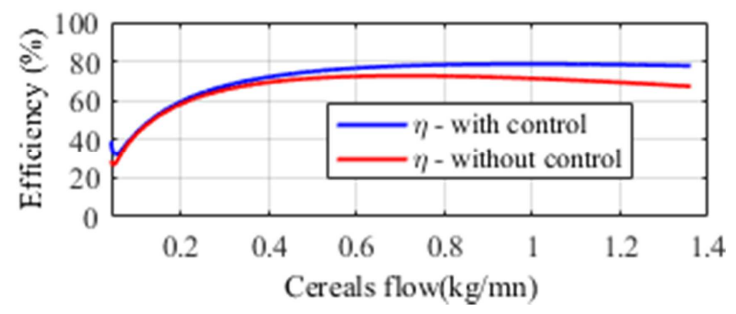

Figure 13. Efficiencies versus cereals flow comparison.

Figure12 shows the operating speeds of the cereals grinding system with and without control. The operating speed converge to the reference perfectly. The tracking is quite satisfactory for controlling system operating speed. The possibility to control operating speed limits flour losses and improves cereals grinding system efficiency. Efficiencies comparison between the proposed and the conventional cereals grinding systems under various loads are shown in Figure 13 Result exhibits that the proposed cereals grinding system has higher efficiency than the conventional system. Results also illustrate that for having a good efficiency, the mill must operate at rated load with a perfect speed control. In conclusion to simulations, the results show the good performances of controllers. In addition to the advantages of power factor correction, reduction of the harmonic distortion and output voltage regulation, the efficiency is significantly improved.

\section{Conclusion}

In this paper, we have discussed the problem of designing and controlling a converter to interface a cereals grinding system and a single-phase PV/battery microgrid. A controlled $\mathrm{AC} / \mathrm{DC} / \mathrm{AC}$ converter was proposed. The detailed operating principles and analytical models of the system are provided in this document. . As for controls, two strategies with multiple control loops system based on power factor control and field oriented control were designed accordingly in order to obtain a unity power factor, to regulate the DC-link voltage and to regulate the operating speed of the cereals grinding system. The models of the power converter and the cereals grinding systems and its control were implemented under Simulink. The results show that the proposed controls achieve the fixed objectives: The obtained current harmonic distortion is significantly reduced. A unity power factor is obtained and the efficiency of the cereals grinding system is improved significantly.

\section{Appendix}

Table 1. Simulation parameters.

\begin{tabular}{ll}
\hline MGs parameters & Motor Parameters \\
\hline $\mathrm{A}_{\mathrm{PV}}=10 \mathrm{~m}^{2}$ & $\mathrm{~L}_{\mathrm{m}}=259.836 \mathrm{mH}$ \\
$\beta=0.0037 /{ }^{\circ} \mathrm{C}$ & $\mathrm{L}_{\mathrm{s}}=270.315 \mathrm{mH}$ \\
$\eta_{\text {inv }}=90 \%$ & $\mathrm{~L}_{\mathrm{r}}=270.315 \mathrm{mH}$ \\
$\mathrm{T}_{\mathrm{C}(\mathrm{STC})}=25^{\circ} \mathrm{C}$ & $\mathrm{R}_{\mathrm{r}}=4.446 \Omega$ \\
$\eta_{\mathrm{PVS}}=85 \%$ & $\mathrm{R}_{\mathrm{s}}=2.4751 \Omega$ \\
$\mathrm{r}_{\mathrm{L}}=0.808 \Omega$ & $\mathrm{f}_{\mathrm{r}}=0.0026 \mathrm{Nm} \cdot \mathrm{s}^{\circ} \cdot \mathrm{rad}^{-1}$ \\
$\mathrm{~L}=3 \mathrm{mh}$ & $\mathrm{J}=0.023 \mathrm{~kg} \cdot \mathrm{m}^{2}$ \\
\hline
\end{tabular}

\section{Nomenclature}

Pload - Total power consumed by the loads

$\mathrm{P}_{\mathrm{PV}} \quad$ - $\quad$ Power generated by the PV system;

$P_{\text {st }} \quad$ - Power flowing from/to the storage system

$\eta_{\text {inv }} \quad$ - Inverter efficiency

$\mathrm{A}_{\mathrm{PV}} \quad$ - $\quad$ Photovoltaic system area

$\mathrm{T}_{\mathrm{a}} \quad$ - Ambient temperature

$\mathrm{G}$ - Solar irradiation

$\eta_{\text {CGS }} \quad$ - Efficiency of cereals grinding system

$\eta_{\text {cha }} \quad$ - Battery efficiency during charging state

$\eta_{\text {dis }} \quad$ - Battery efficiency during discharging state

$\eta_{\text {PVS }} \quad$ - Maximum power point efficiency

$\mathrm{U}_{\text {bus }} \quad$ - Nominal DC-link bus voltage

$\mathrm{C}_{\mathrm{n}} \quad$ - Nominal capacity of battery storage

B - Temperature coefficient

$\mathrm{v}_{\mathrm{sd}} \quad$ - Voltage stator component in $\mathrm{d}$ axis

$\mathrm{v}_{\mathrm{sq}} \quad$ - Voltage stator component in q axis

$i_{\text {sd }} \quad$ - Current stator component in $\mathrm{d}$ axis

$\mathrm{i}_{\mathrm{sq}} \quad$ - Current stator component in q axis

$\phi_{\text {rd }} \quad$ - Rotor flux component in $\mathrm{d}$ axis

$\phi_{\mathrm{rq}} \quad$ - Rotor flux component in q axis

$\mathrm{L}_{\mathrm{s}} \quad$ - Stator inductance

$\mathrm{L}_{\mathrm{r}} \quad$ - Rotor inductance

$\mathrm{L}_{\mathrm{m}} \quad$ - Mutual inductance

$\mathrm{R}_{\mathrm{s}} \quad$ - $\quad$ Stator resistance

$R_{r} \quad-\quad$ Rotor resistance

$\mathrm{J} \quad$ - Moment of inertia.

$\omega_{\mathrm{s}}, \quad-\quad$ Synchronous speed

$\Omega \quad$ - $\quad$ Rotor speed

$\Omega \quad$ - Mechanical speed

$f_{r} \quad-\quad$ Friction coefficient

$P \quad$ - Number of poles pairs

$\mathrm{T}_{\mathrm{e}} \quad$ - Electromagnetic torque

$\mathrm{Q} \quad$ - Cereals flow

$v_{d c} \quad-\quad$ DC-link voltage

$\mathrm{L} \quad$ - Input inductance

$K \quad$ - $\quad$ Switching function of rectifier switches

$i_{g} \quad$ - Current of the microgrid

$i_{s} \quad$ - Input current of the voltage inverter

C - Output DC-link capacitor

$\xi \quad$ - Damping factor

$\omega_{c i} \quad$ - Natural frequency of rectifier current loop

$\omega_{c v} \quad$ - Natural frequency of rectifier voltage loop

$\omega_{\mathrm{c}} \quad$ - Own pulsation the closed-loop speed 


\section{References}

[1] L. Thiaw, G. Sow, and S. Fall, "Application of Neural Networks Technique in Renewable Energy Systems," 2014 First Int. Conf. Syst. Informatics, Model. Simul. Appl., pp. 612, $2014 \quad$ [Online]. Available: http://dx.doi.org/10.1109/SIMS.2014.12.

[2] D. R. Thiam, "Renewable decentralized in developing countries: Appraisal from microgrids project in Senegal," Renew. Energy, vol. 35, no. 8, pp. 1615-1623, 2010 [Online]. Available: http://dx.doi.org/10.1016/j.renene.2010.01.015.

[3] T. Kobayakawa and T. C. Kandpal, "Photovoltaic micro-grid in a remote village in India: Survey based identification of socio-economic and other characteristics affecting connectivity with micro-grid," Energy Sustain. Dev., vol. 18, no. 1, pp. 28-35, 2014 [Online]. Available: http://dx.doi.org/10.1016/j.esd.2013.11.002.

[4] B. K. Das, N. Hoque, S. Mandal, T. K. Pal, and M. A. Raihan, "A techno-economic feasibility of a stand-alone hybrid power generation for remote area application in Bangladesh," Energy, vol. 134, pp. 775-788, 2017 [Online]. Available: http://dx.doi.org/10.1016/j.energy.2017.06.024.

[5] T. Kobayakawa and T. C. Kandpal, "Analysis of electricity consumption under a photovoltaic micro-grid system in India," Sol. Energy, vol. 116, pp. 177-183, 2015 [Online]. Available: http://dx.doi.org/10.1016/j.solener.2015.04.001.

[6] T. Kobayakawa and T. C. Kandpal, "Optimal resource integration in a decentralized renewable energy system: Assessment of the existing system and simulation for its expansion," Energy Sustain. Dev., vol. 34, pp. 20-29, 2016 [Online]. Available: http://dx.doi.org/10.1016/j.esd.2016.06.006.

[7] H. Camblong et al., "Micro-grids project, Part 1: Analysis of rural electrification with high content of renewable energy sources in Senegal," Renew. Energy, vol. 34, no. 10, pp. 2141-2150, 2009 [Online]. Available: http://dx.doi.org/10.1016/j.renene.2009.01.015.

[8] M. Ikeda and T. Hiyama, "Simulation studies of the transients of squirrel-cage induction motors," IEEE Trans. Energy Convers., vol. 22, no. 2, pp. 233-239, 2007 [Online]. Available: http://dx.doi.org/10.1109/TEC.2006.874203.

[9] W. L. Silva, A. M. N. Lima, and A. Oliveira, "A method for measuring torque of squirrel-cage induction motors without any mechanical sensor," IEEE Trans. Instrum. Meas., vol. 64, no. 5, pp. 1223-1231, May 2015 [Online]. Available: https://doi.org/10.1109/TIM.2014.2371192. [Accessed: 07Dec-2018].

[10] S. Padmanaban et al., "Wavelet-fuzzy speed indirect field oriented controller for three-phase AC motor drive Investigation and implementation," Eng. Sci. Technol. an Int. $J$. , vol. 19, no. 3, pp. 1099-1107, 2016 [Online]. Available: http://dx.doi.org/10.1016/j.jestch.2015.11.007.

[11] S. Whaite, B. Grainger, and A. Kwasinski, "Power quality in DC power distribution systems and microgrids," Energies, vol. 8, no. 5, pp. 4378-4399, 2015 [Online]. Available: http://dx.doi.org/http://dx.doi.org/.

[12] M. H. Amrollahi and S. M. T. Bathaee, "Techno-economic optimization of hybrid photovoltaic/wind generation together with energy storage system in a stand-alone micro-grid subjected to demand response," Appl. Energy, vol. 202, pp. 6677, 2017 [Online]. Available: http://dx.doi.org/10.1016/j.apenergy.2017.05.116.

[13] A. Maleki and A. Askarzadeh, "Comparative study of artificial intelligence techniques for sizing of a hydrogen-based standalone photovoltaic / wind hybrid system," Int. J. Hydrogen Energy, vol. 39, no. 19, pp. 9973-9984, 2014 [Online]. Available: http://dx.doi.org/10.1016/j.ijhydene.2014.04.147.

[14] A. Ghafoor and A. Munir, "Design and economics analysis of an off-grid PV system for household electrification," Renew. Sustain. Energy Rev., vol. 42, pp. 496-502, 2015 [Online]. Available: http://dx.doi.org/10.1016/j.rser.2014.10.012.

[15] Y. Bakelli, A. Hadj Arab, and B. Azoui, "Optimal sizing of photovoltaic pumping system with water tank storage using LPSP concept," Sol. Energy, vol. 85, no. 2, pp. 288-294, 2011 [Online]. http://dx.doi.org/10.1016/j.solener.2010.11.023.

[16] M. Zaibi, "Smart power management of a hybrid photovoltaic / wind stand-alone system coupling battery storage and hydraulic network," vol. 146, pp. 210-228, 2018 [Online]. Available: http://dx.doi.org/10.1016/j.matcom.2016.08.009.

[17] F. Mehazzem, A. L. Nemmour, and A. Reama, "Real time implementation of backstepping-multiscalar control to induction motor fed by voltage source inverter," Int. J. Hydrogen Energy, vol. 42, no. 28, pp. 17965-17975, 2017 [Online]. Available: http://dx.doi.org/10.1016/j.ijhydene.2017.05.035.

[18] Z. Kandoussi, Z. Boulghasoul, A. Elbacha, and A. Tajer, "Sensorless control of induction motor drives using an improved MRAS observer," J. Electr. Eng. Technol., vol. 12, no. 4, pp. 1456-1470, 2017 [Online]. Available: http://doi.org/10.5370/JEET.2017.12.4.14561456.

[19] Z. M. S. El-Barbary, "Single-to-three phase induction motor sensorless drive system," Alexandria Eng. J., vol. 51, no. 2, pp. 77-83, 2012 [Online]. Available: http://dx.doi.org/10.1016/j.aej.2012.05.003.

[20] M. Diop, W. Khiari, L. Thiaw, M. Turki, and J. Belhadj, "Characterization and control of a craft mill driven by induction motor fed by photovoltaic mini-grid," Proc. Int. Conf. Recent Adv. Electr. Syst. Tunis., pp. 119-124, 2016 [Online]. Available: http://journal.esrgroups.org/jes/icraes/IcraesProceedings.html.

[21] T. Ma, H. Yang, L. Lu, and J. Peng, "Optimal design of an autonomous solar-wind-pumped storage power supply system," Appl. Energy, vol. 160, pp. 728-736, 2015 [Online]. Available: http://dx.doi.org/10.1016/j.apenergy.2014.11.026.

[22] F. Farhani, A. Zaafouri, and A. Chaari, "Real time induction motor efficiency optimization," J. Franklin Inst., vol. 354, no. 8, pp. 3289-3304, 2017 [Online]. Available: http://dx.doi.org/10.1016/j.jfranklin.2017.02.012.

[23] A. Ghosh, S. Ganesh Malla, and C. Narayan Bhende, "Smallsignal modelling and control of photovoltaic based water pumping system," ISA Trans., vol. 57, pp. 382-389, 2015 [Online]. http://dx.doi.org/10.1016/j.isatra.2015.01.008.

[24] M. Fateh and R. Abdellatif, "Comparative study of integral and classical backstepping controllers in IFOC of induction motor fed by voltage source inverter," Int. J. Hydrogen Energy, vol. 42, no. 28, pp. 17953-17964, 2017 [Online]. Available: http://dx.doi.org/10.1016/j.ijhydene.2017.04.292. 